\title{
Conformational Proteomics of Macromolecular Architecture
}

Approaching the Structure of

Large Molecular Assemblies and

Their Mechanisms of Action 
This page intentionally left blank 
R. Holland Cheng \& Lena Hammar, editors

Karolinska Institutet, Sweden

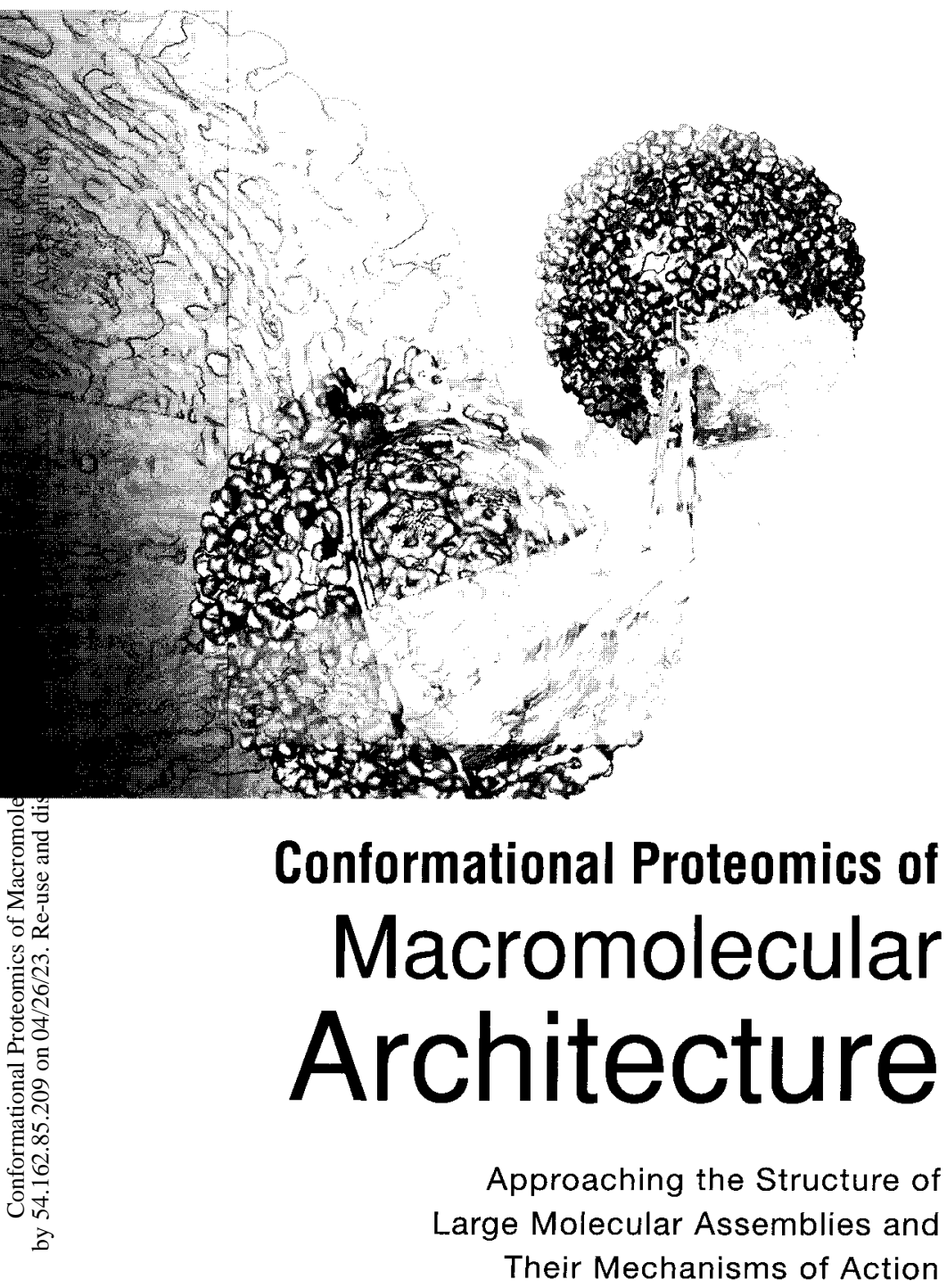


Published by

World Scientific Publishing Co. Pte. Ltd.

5 Toh Tuck Link, Singapore 596224

USA office: Suite 202, 1060 Main Street, River Edge, NJ 07661

UK office: 57 Shelton Street, Covent Garden, London WC2H 9HE

\section{British Library Cataloguing-in-Publication Data}

A catalogue record for this book is available from the British Library.

To give full credit to the unique structural information given in illustrations, an all color electronic version is enclosed, see attached CD.

CONFORMATIONAL PROTEOMICS OF MACROMOLECULAR ARCHITECTURE

Approaching the Structure of Large Molecular Assemblies and Their Mechanisms of Action (With CD-Rom)

Copyright $@ 2004$ by World Scientific Publishing Co. Pte. Ltd.

All rights reserved. This book, or parts thereof, may not be reproduced in any form or by any means, electronic or mechanical, including photocopying, recording or any information storage and retrieval system now known or to be invented, without written permission from the Publisher.

For photocopying of material in this volume, please pay a copying fee through the Copyright Clearance Center, Inc., 222 Rosewood Drive, Danvers, MA 01923, USA. In this case permission to Cु photocopy is not required from the publisher.

ISBN 981-238-615-7 (pbk) 


\section{PREFACE}

In this book we have gathered a few examples of macromolecular architectures that elaborate their machinery in biological systems. The invited authors are selected among the excellent ones performing in the frontline of their fields. The aim is to present to the young generation of researchers the fascination of structural science. It is also an attempt to provide background knowledge and theories for discussions at the forum of structural dynamics.

Above all, this book is dedicated to the young scientists and freshmen researchers on their way into dedicated studies. With this selection of articles from the wild and progressive biological field it is our hope that the book can find its way to students in advanced structural sciences and conformational proteomics. Hopefully, it will serve as a platform for seminars and discussions, and provide a platform for future explorers.

The selection covers a portion of today's structural biology, focusing on dynamic aspects on the large macromolecular assemblies. Among these are the viruses, the ribosome, the giant enzymes, and the molecular machineries for moving around. We stress the importance of the tools, the ways and means by which to acquire new information and knowledge. Therefore the selection of articles is also aimed to illustrate contemporary techniques at their present best, in a fast developing stage as they are. It is fascinating to find that biological science and technology is so well integrated in the minds of those that dwell in the frontline actively advancing the field.

\section{Dynamic Architectures}

In the mid of the last century there was a gap between high and low resolution - the small molecules were seen by X-ray crystallographers and the large structures by electron microscopists, both handling brakethrough techniques in structural biology. In the gap between them a new field developed, where details down to the atomic level could gradually be mapped and understood in their surroundings. Where the building blocks of the large molecular architectures of life could be revealed, and 
the construction be appreciated. - We now have a long record of macromolecular architectures revealed in detailed structure. Thus, high and low-resolution methods are converging, and additional ones appear. Along with that comes the quiz of dynamics, the functionality, and the structure in action, locomotion. Actually, it is with the structure action is $\approx \div$ performed. Therefore we now search not only the details of the structure or the beauty of the architectonic construction per se, but the nature of its embedded dynamics!

Today, we have acquired methods allowing snapshots of life events, glimpses of the machinery of giant molecules, membrane intercomunication and other macromolecular architectures. Around the corner one can envision what to be understod as life systems. That is the assembly in its biological environment, in the cell, in the tissue and the body. The comprehendable information from high and low resolution structural methods have come more close than ever before. The development of real time techniques and the nanotechnology makes science more exciting than ever. In this volume a selection of the visionaries, with their strong knowledge and elegant tools, present to you a few of the present day's frontlines in the dynamic structural science.

\section{The Theory of Quasi-equivalence}

Through more than 40 years the theorem of Don Caspar and Aron Klug has guided our structural thinking. Plain and simple in its approach, the theory of quasi-equivalence brings us into the futuristic structural virology - the simple insight that the possibilities lay there in the deviations as well as in the perfect lattice (Caspar D, and Klug A. Cold Spring Harbor Symposia on Quantitative Biology, XXVII: 1-24, 1962). It appeared in the search for a common construction principle of virus capsids. It is timely that we here can present in the beginning of this volume a historian's summery on how the insight emerged together with Don Caspar's present view on its usefulness. The latter is further supported by second generation's studies in this realm, as seen throughout this volume. A virus structure database, based on the nomination standard originating from the theorem is available and is presented in the last chapter. 


\section{Approaching Large Assemblies in Membranes}

Membranes continue to fascinate us by their dynamic character and capacity to create compartments for different cellular activities. They provide a support for assembly of large molecular constructs and contain the complicated water channel. To solve the structure of these requires method innovators at their best, as presented in the Chapters 5-7.

\section{Protein Shuttle}

The evolution has created specialized transport and communication systems between membrane compartments. The clathrin with its companion represent a cellular assembly designed to recycle multiple membrane receptors; An adoptable cage of polyhedral shape that has been in the textbooks for years, but only recently been understood in some detail (Chapter 8).

\section{Molecular Machines}

Giant Enzymes, Ribosome, and Motion engines can all be regarded as Complex Macromolecular Machines (Chapters 9-16). It is striking that several giant enzymes, elaborating with multi-copies of a few components, shares architectonic designs and dynamic constructions with viruses. Contrasting to that is the ribosome, the master of concerted activity. Like a very efficient printing office for peptide polymers, it is constructed from a multitude of different pieces acting together. Here, motion of individual parts reveals some of its dynamic logic. Two motion engines are presented, the propeller motion device of the bacterial flagella (Chapter 15) and the muscular engine for our own motion (Chapter 16). Both structures, the result of masterly teamwork and dedicated in要 sight in dynamics, exemplify the role of conformational quasiequivaUn है

\section{Conformational Proteomics}

The proteomics part of our approach is considerable, which demands new and refined tools for data acquisition. This is amply exemplified in 
the different chapters of this volume. Some tools and comments are provided in the last section (Chapters 17-20).

\section{Acknowledgements}

As editors we would like to express our gratitude to the chapter authors who have devoted enormous efforts to fulfill the goals of this book. Their dedication and positivism has been truly stimulating, and made the editing of this work an exciting experience. We also like to thank all the participants of the Structural Forum at Karolinska Institute for venting contemporary problems in structural biology, and thereby provide a base for this selection of articles, and Amersham-Biotech Inc. and CristalResearch $\mathrm{AB}$, for their contributions. Special thanks are due to professore eremite Bror Strandberg, Uppsala, and Björn Afzelius, Stockholm, pioneers in Swedish crystallography and electron microscopy, respectively, for sharing with us their never ending scientific enthusiasm and support in this project. The publisher is worth great appreciation for creative support throughout the collaboration on this volume.

. R Holland Cheng, PhD

Professor of Molecular and Cellular Biology

Adv Microscopy \& Proteomics

University of California

Briggs Hall, Davis, CA 95616 , USA

rhch@ucdavis.edu 구

Karolinska Institute

Structural Virology

Novum, Hälsovägen 7

Huddinge, SE 14157, Sweden

holland.cheng@biosci.ki.se

Holland Cheng and Lena Hammar

Lena Hammar, $\mathrm{PhD}$

Associate Professor in

Biochemistry

Karolinska Institute

Structural Virology

Novum, Hälsovägen 7

Huddinge, SE 14157, Sweden

lena.hammar@biosci.ki.se 


\section{CONTENTS}

PREFACE

PART I. GEOMETRY AND ACTION IN VIRUSES

Chapter 1. Early Theories of Virus Structure

Gregory J. Morgan

Chapter 2. Quasi-Equivalence and Adaptability in Living

Molecular Assemblies

Donald L. Caspar and Lena Hammar

Chapter 3. The Role of Disordered Segments in Viral

Coat Proteins

Lars Liljas

Chapter 4. Prefusion Dynamics in an Enveloped

Virus - Alphavirus Model

Lena Hammar, Lars Haag, Bomu Wu and

R. Holland Cheng

PART II. APPROACHING LARGE ASSEMBLIES IN MEMBRANES

Chapter 5. Strategy to Obtain High Resolution Structure of Membrane Proteins by X-ray Crystallography

Hiroshi Aoyama, Eiki Yamashita, Keisuke Sukarai and Tomitake Tsukihara

Chapter 6. On the Possibility of Determining Structures of Membrane Proteins in Two-Dimensional Crystals Using X-Ray Free Electron Lasers

Michael Becker and Edgar Weckert 
Chapter 7. Functional Details on Membrane Proteins Observed Through an Electron Beam Yoshinori Fujiyoshi

PART III. PROTEIN SHUTTLE

Chapter 8. Clathrin and Companions Barbara Pearse

PART IV. GIANT ENZYMES

Chapter 9. Multifunctional Enzyme Complexes: Multistep Catalysis by Molecular Machines Richard N. Perham

Chapter 10. Metamorphosis of an Enzyme Rudolf Ladenstein, Winfried Meining, Xiaofeng Zhang, Markus Fischer and Adelbert Bacher

Chapter 11. Optimizing an Enzyme for Its Physiological Role: Structural and Functional Comparisons of ATP Sulfurylases from Three Different Organisms Andrew J. Fisher, Ian J. Macrae, John D. Beynon, Eric B. Lansdon and Irwin H. Segel

PART V. RIBOSOMES

Chapter 12. Ribosomal Crystallography: Dynamics, Flexibility and Peptide Bond Formation Ada Yonath

Chapter 13. The Dynamics of the Ribosome as Inferred by Cryo-EM: Induced and Self-Organized Motions Joachim Frank 
Chapter 14. How do Translation Factors Catalyze Protein Synthesis

Martin Laurberg, Ole Kristensen, Maria Selmer, Xiao-Dong Su and Anders Liljas

\section{PART VI. MOTION ENGINES \\ Chapter 15. Dynamic Aspects of the Bacterial Flagellum Keiichi Namba \\ Chapter 16. Myosin Polymorphism and Muscle Contraction} Kenneth C. Holmes and Rasmus R. Schroeder

PART VII. AROUND THE BENCH PROTEOMICS

Chapter 17. Is Crystallization a "Bottleneck" of Modern Structural Crystallomic?

Jan Sedzik

Chapter 18. Sensor Surface Interactions in the Study of Macromolecular Assemblies

José M. Casasnovas, Sevak Markarian and Lena Hammar

Chapter 19. PPiDB - A Protein-Protein Interactions Database Prasanna R. Kolatkar and Lin Kui

Chapter 20. Virus Particle Explorer (VIPER): A Repository of Virus Capsid Structures

Vijay S. Reddy, Padmaja Natarajan, Gabriel Lander, Chunxu Qu, Charles L. Brooks, III and John E. Johnson 